\title{
LA HISTORIA VERDADERA DE ÁLVAR NÚÑEZ CABEZA DE VACA EN LA ÚLTIMA NOVELA DE ABEL POSSE, EL LARGO ATARDECER DEL CAMINANTE
}

\author{
POR \\ Seymour Menton \\ University of California, Irvine
}

De acuerdo con las teorías de Borges, de Hayden White y de todos los que nos hemos contagiado de lo posmoderno, el discurso histórico no es más verídico que el discurso novelístico. En la nueva Nueva Novela Histórica de Abel Posse, El largo atardecer del caminante (1992), Álvar Núñez Cabeza de Vaca emprende su última caminata en Sevilla un año antes de morirse escribiendo la verdadera historia de sus propias andanzas en La Florida y México lo mismo que en el Brasil y Paraguay. Con una buena dosis de metaficción, el viejo conquistador caminante desmiente y complementa su propia crónica Naufragios y comentarios, tal como Bernal Díaz del Castillo escribió a los noventa años la verdadera historia de la conquista de la Nueva España desmintiendo al cronista López de Gómara. Refiriéndose a los seis años pasados entre los indios de La Florida, ${ }^{1}$ el viejo caminante señala de la manera más franca la increible omisión en Naufragios de sus experiencias entre los indios: "Releyéndome ahora, encuentro que mi silencio de seis años resuelto con página y media de mi libro, es lo suficientemente descarado y evidente como para que los estúpidos inquisidores de la Real Audiencia y del Consejo de Indias no sospechasen nada" (78). Es decir que el conquistador peatón, y otros conquistadores y cronistas, pese a su proximidad a los sucesos narrados no podían escribir la verdad en su discurso histórico por miedo a las consecuencias a manos de la Inquisición o del Emperador y sus oficiales. Si la novela de Posse resulta más verídica que la crónica escrita por su propio protagonista, Posse no comete la imprudencia de convertir esta situación en la norma de toda creación literaria. Por eso, incluye en su novela al único personaje anacrónico, el Marqués de Bradomín, protagonista de las cuatro sonatas de Valle-Inclán. Con las fabulaciones de Bradomín, sobre todo respecto a la pérdida de su brazo, el viejo caminante-escritor comenta que "lo más fascinante de la mentira literaria es la facultad para acumular detalles. La historia termina siendo más interesante que la verdad" (103). El ejemplo que utiliza Posse destaca por su tono melodramático que contrasta con el tono sincero del viejo Cabeza de Vaca: “Achispado con el vino fresco volvió a contar la historia de la pérdida de su brazo durante sus supuestas aventuras por México... Perseguido por feroces olmecas se refugia en una caverna y allí una tigra recién parida le arranca el brazo creyendo que atacaría la cría" (102-103).

\footnotetext{
${ }^{1}$ La Florida abarcaba toda la zona del Golfo de México incluyendo los estados actuales de Florida,
} Alabama, Mississippi, Louisiana y Texas. 
En cuanto a las verdades omitidas de Naufragios y comentarios y reveladas en la nueva novela de Posse, se destacan tres. El náufrago se adapta a la vida indígena llegando a querer a la joven Amaría, regalada por su tío, el Jefe Dulján. Desconociendo el concepto religioso del pecado, ella goza de las relaciones sexuales procurando la mayor sensualidad: "Ambos cuerpos ingresan demoradamente en la esfera de la sensualidad y se apoyan mutuamente sin ya existir macho o hembra. Es como un solo ser rodando por una pendiente de delicias"(96). El náufrago también demuestra un verdadero afecto paterno hacia los dos hijos mestizos: el niño Amadís y la niña Nube. En efecto, hacia el final de la novela, descubre a su hijo enjaulado en Sevilla destinado con otros indios a ser mandados a la Universidad de Lovaina y los rescata mediante la venta de su casa quedando totalmente empobrecido.

Durante los seis años que Cabeza de Vaca pasa con la tribu de Dulján, llega a ser su consejero militar y su curandero despertando envidia entre los otros indios a tal punto que Dulján le aconseja partir en busca de las Siete Ciudades de Cibola con dos españoles, Castillo y Andrés Dorantes, y el moro/negro Estebanico. En su travesía de dos años por los estados actuales de Texas, Nuevo México y Arizona, Álvar Núñez camina desnudo y descalzo curando a los indios mediante oraciones católicas y demás recursos aprendidos durante sus seis años de convivencia con los indios de La Florida. Aunque algo de esto se narra en Naufragios, muchos detalles se omiten por miedo a la Inquisición.

Uno de los mayores secretos revelados en la novela es que Álvar Núñez nunca llegó a encontrar El Dorado ni las Siete Ciudades de Quivira o de Cibola, secreto que no reveló ni al viejo cronista Gonzalo Fernández de Oviedo ni al Emperador Carlos V en el monasterio de Yuste. Lo que sí revela en la novela es que habiendo ganado la confianza de los indios tarahumaras en el norte de Chihuahua, ellos le dieron una sustancia alucinógena para masticar que le dio durante tres días "una gran lucidez" (174) que hasta le permitió ver cómo su padre lo engendró con su madre. Con esa experiencia, se acabó la aventura y pronto se reencuentra con soldados españoles del gobernador de la Nueva Galicia (Jalisco), Nuño de Guzmán.

En realidad, la revisión o la ampliación de Naufragios y comentarios es sólo un hilo de la novela y está subordinado al acto de escribir que constituye el eje estructurante de toda la novela desde el principio hasta el fin. Desde el primer capítulo, Lucia de Aranha le sirve al protagonista de inspiración. Ella ha leído sus memorias y tiene ganas de saber la historia completa y verdadera. Influido Álvar Núñez por su idealismo quijotesco - "Se sabe que era alto, de músculos correosos, con barba valleinclanesca y aquiJotado" (prólogo, 12), le cambia el nombre a Lucindas. Ella le regala "una resma de papel imitación pergamino... En cada folio hay un escudo de agua que transparenta la insignia de los Cabeza de Vaca" (34). Sentado en su cuarto o en la azotea, Álvar Núnez emprende la "inesperada jornada 'literaria' de mi vida que se origina en la resma de papel de Lucinda" (53). Trata de escribir dos o tres cuartillas cada día. El acto de escribir lo exalta a tal punto que desde hace más de un mes se despierta muchas veces "con fuertes erecciones" (48). A veces, la tarea es relativamente fácil: "No puedo decirle las cosas a Lucinda tal como las confío a la pluma en estos días largos y sosegados de mi caminata por el papel" (65). En otras ocasiones, es más dificil: "Visitar a punta de pluma mi pasado es un viaje tan cansador como cualquier otra jornada" (111). E1 uso metafórico de la caminata para el acto de escribir se mantiene a través de toda la novela: "caminante que anda por las cuartillas de Lucinda" (235). En la última página 
de la novela, el protagonista compara sus memorias con "un mensaje arrojado al mar del tiempo" (262) y termina con otra metáfora marítima: "Espero que esta nave no naufrague y llegue a buen lector. Al fin de cuentas el peor de todos los naufragios sería el olvido"(262).

En realidad, la novela de Posse es mucho más que una versión ampliada de Naufragios $y$ comentarios. Se trata de la humanización de un personaje histórico en vísperas de su muerte. En ese sentido se podría comparar con El general en su laberinto de García Márquez y la segunda parte de El arpa y la sombra de Carpentier. Al escribir sus verdaderas memorias, Álvar Núñez trata de recordar “¿quién era Álvar Núñez en aquel entonces?”(18), reconociendo que el ser humano cambia constantemente: "Nuestros sucesivos nosotros, que se nos van muriendo por el camino" (24). Sin embargo, Álvar Núñez se destaca en la novela como el único conquistador bueno. Es el único conquistador peatón en contraste con los jinetes Cortés y De Soto. Es el único conquistador que no mató a ningún indio - "en diez años de andanzas no había matado un solo indio" (207)- que trató a los indios como seres humanos, tratando de comprenderlos y de ayudarlos: "sólo la fe cura, sólo la bondad conquista" (208). Cuando el cronista Gonzalo Fernández de Oviedo le pregunta "¿Quiénes son esos misteriosos nosotros?" (32), Álvar Núñez da a entender que es el primer mestizo cultural: "los que ya no podemos ser ni tan indios ni tan cristianos" (32). Su único "correligionario" es el cronista Pedro Cieza de León quien presenció el fusilamiento de los dioses gigantescos de Tiahuanaco por los españoles: "A su modo, se transformó en un 'otro'. Ni tan español ni indio"' (212).

La caracterización positiva de Álvar Núñez se refuerza con la condena de los conquistadores crueles y violentos comenzando con su propio abuelo Pedro de Vera, quien estableció el paradigma para la conquista al someter las Canarias ordenando "colgar a los caciques guanches de las orejas y de los pulgares contra el muro ardiente del castillo" (18). La complicidad entre la espada (el puñal) y la cruz, tan difundida gracias a los frescos de Diego Rivera y transformada en "cruzhorca" por el mismo Posse en Los perros del Paraíso, vuelve a destacarse en las palabras novelísticas de Cabeza de Vaca: "De este modo daba lo mismo lo que hiciera Cortés o Pizarro o Álvarado o ineptos como yo -que soy un mal militar - o cualquier capitán improvisado que se cree un Aníbal. Los americanos, los aborígenes, quedaban derrotados ante nuestra simple presencia, antes de que entren a actuar la cruz y la cruz de los puñales" (182).

O sea que el verdadero secreto de Cabeza de Vaca no fue la experiencia alucinógena en las Siete Ciudades de Cibola sino la revelación poco antes de zarpar de Veracruz en 1537 de que "es el mal que prevalece en nuestra cultura" (183); "el Demonio nos precede, hagamos lo que hagamos. Seamos un Pizarro o intentemos, como en mi caso, defender que 'sólo la bondad conquista"' (182). Esa revelación, con la cual se cierra la Tercera Parte de la novela, podría llevar a Cabeza de Vaca "a la hoguera inquisitorial" (183). Es una revelación percibida sólo por el nuevo hombre mestizo, el nosotros o "el otro" en terminología actual. El protagonista de Posse reconoce eso al decir: "un secreto para nosotros. O para hombres de otra época, no de ahora" (184).

También de acuerdo con los "hombres de otra época", o sea nosotros los contemporáneos de Posse, Cabeza de Vaca da un sesgo ecológico a la condena de la violencia española. En el Paraguay observa con repugnancia cómo los españoles atrapan un pez maravilloso y 
luego lo arrojan a la playa para que muera. "¿Qué profunda maldición cainita mueve a los hombres de esta arrogante 'civilización' conquistadora?" (219).

Tanto como Los perros del Paraiso, Noticias del imperio y otras Nuevas Novelas Históricas, El largo atardecer del caminante cuestiona la interpretación tradicional o decimonónica de la dicotomía de "civilización y barbarie". Después de su primer naufragio, Cabeza de Vaca se da cuenta de la superioridad tanto moral como científica de los "bárbaros": "los bárbaros - esos que mataban por centenas hombres como Narváez o Pizarro para establecer la verdadera fe- eran quienes lloraban por mi desamparo, condoliéndose de nuestra inhabilidad y desdicha. Nosotros, los dominadores del mundo desnudos y sin coraza ni espada, debíamos aprender de los salvajes a coger peces y raíces no venenosas" (75). El cacique Dulján resulta "ser mejor persona que el chanchero Pizarro que asesinó a Atahualpa" (85).

Por haber convivido con los indios, Cabeza de Vaca está dispuesto a contemplar la naturaleza americana con la misma actitud simbiótica de los indios, comparándola con el Paraíso Terrenal que descubrió Colón y el Paraíso Terrenal paraguayo: — “estábamos cruzando el Paraíso primordial" (224).

No obstante todo lo que ya he dicho, lo que más fascina de esta novela es cómo se distingue tanto de Los perros del Paraíso como de la mayoría de las Nuevas Novelas Históricas: ni es totalizante ni es neobarroca. Con énfasis casi exclusivo en el protagonistanarrador que narra en el presente de 1657 en Sevilla, Posse logra dar vida a ese momento tan importante de transición entre Carlos V y Felipe II, entre los conquistadores y los gobernadores de América. Al caminar por los muelles del Guadalquivir, Álvar Núñez nota el movimiento frenético. Aldescribir los nuevos productos americanos, utiliza la enumeración multisensorial de Carpentier pero de una manera menos erudita y más personal:

Seguí más allá, hacia el muelle de los grandes bastimentos de Indias: azúcar, aromáticas especias, cacao, piedras medicinales, pieles curtidas, plumas exóticas y hasta sagradas como las del quetzal - que, según dicen, las reclaman a cualquier precio las putas finas de Venecia y de la corte borgoñona. Me gusta demorarme en ese muelle. Me apoyo contra los altos fardos de hojas secas de tabaco y aspiro profundamente el olor de aquella América. Las balas de goma látex, el susurro de las bolsas de porotos. Pero lo que más me gusta es hundir la mano abierta en los granos de cacao y aspirar el aroma denso (41).

Cientos de personas que seguirán trabajando incluso entrada la noche. Redes, guinches, cargas, risas, martillazos, imprecaciones. Los sonidos se ahogan en la corriente lacia del Guadalquivir, anochece. Desde los castillos de popa, contramaestres tratando de hacerse oír, contadores de lápiz atento y de vez en cuando la silueta de algún capitán que bosteza aburrido debajo de su tricornio con vistosas plumas americanas.

Quien vaya alguna vez por el Arenal podrá irse haciendo una idea más o menos clara del mundo en que vivimos (43).

Otro factor que distingue la presentación del medio ambiente por Posse de la mayor investigación arqueológica y de mayor complejidad estilística de Alejo Carpentier y Homero Aridjis es la observación por Álvar Núñez de los cambios ocurridos en Sevilla desde su infancia. Nacido en Jerez, Álvar Núñez se crió en la finca de Extremadura con visitas a Sevilla. Hasta parece recordar la llegada triunfal de Cristóbal Colón en 1493 
cuando él tenia sólo tres años. Aunque dice "era muy niño, no recuerdo casi nada" (100), si narra cómo trepado en las espaldas de una de las criadas moriscas pudo ver "el desfile de indios, papagayos, tucanes y tigrillos enjaulados" (100) y una máscara de latón o de oro: "La gente gritaba ‘ ¿Es oro! ¡Oro!’ Y yo sólo vi como un latón más bien sucio que no refulgía ni brillaba" (100). Este segmento también deja una impresión fuerte en el lector por ser la única ocasión en que el almirante se menciona por nombre. Aunque todos los otros conquistadores siempre se mencionan por nombre, a Colón Álvar Núñez suele llamarlo el "genovés descubridor"(21), "genovés aventurero"(97), "genovés sinvergüenzay marrano" (148).

Entre los aspectos más interesantes de esta novela se destaca la serie de encuentros personales de Cabeza de Vaca con el cronista Fernández de Oviedo, con los conquistadores Hernán Cortés y Hernando de Soto y con el mismo emperador Carlos V. A Cortés se le dedica todo un capítulo para presentar el encuentro dos días antes de su muerte en 1547, "avejentado, triste y caído" (151). A pesar de ser nombrado Marqués de Oaxaca, a Cortés el Emperador le negó el puesto de virrey de la Nueva España, y en España no le perdonaron su falta de estirpe noble. Cortés le confiesa a Cabeza de Vaca sus dudas sobre la legitimidad de la Conquista: "A veces me pregunto si no habremos sido como aquellos bárbaros que llegaron a Roma y la sepultaron sin darse cuenta de lo que hacían" (154). Cabeza de Vaca puede compartir las emociones de Cortés porque él también se siente un fracasado: "Tal vez quise ser un conquistador distinto, y eso es imposible. Ni los hombres de iglesia me dejaron. Fracasé" (155). Cabeza de Vaca también evoca en sus memorias sus encuentros anteriores con Cortés en México: recién llegado a Tenochtitlan después de andar descalzo y desnudo ocho años entre los indios con énfasis en el contraste con las "botas finas, de cabritilla" (45) de Cortés. También recuerda cómo Cortés lo había llevado a presenciar la ceremonia del sacrificio de los aztecas en una pirámide de Oaxaca (117).

Cabeza de Vaca también tiene una relación estrecha con Hernando de Soto. En Sevilla éste le convence que debe pedir el puesto de Adelantado en el Río de la Plata, en vez del puesto de Adelantado en La Florida que ambicionaba De Soto por la posibilidad de encontrar las siete ciudades de la Cibola.

El recuerdo de la entrevista con Carlos V cierra la Primera Parte de la novela. Asediado por "el implacable tictac metálico del reloj" (56-57), el moribundo emperador abdicado reconoce la contribución de Cabeza de Vaca y su actitud honrada frente a "esas grandes perfidias" (57) que vio en las Indias - “Estás en el otro extremo de ese demente, el Lope de Aguirre" (57) - y sin embargo, se deja vencer por la indiferencia y Cabeza de Vaca se da cuenta de que ya no vale la pena hablarle de las Siete Ciudades ni de su crónica secreta. En tal vez el único momento en que Abel Posse, a través del narrador Cabeza de Vaca, escribe al estilo muralístico, repasa con orgullo su propia generación: "Y en lo alto el gran rey Carlos, Primero y Quinto. Emperador invencido que murió viendo el deslizamiento de los últimos metálicos segundos, implacables, en el reloj que le trajo el niño don Juan de Austria su hijo e hijo de la bella doncella de Ratisbona" (149). En ese gran salón, gran teatro, Cabeza de Vaca incluye españoles e indios, reyes y sus propios familiares: el rey Fernando, Cortés, Colón, Moctezuma, Dulján, Atahualpa, Amaría, Nube. - "Soy casi ya el bisabuelo de aquel Álvar Núñez que se presentó desnudo el otro día en la azotea” (149). 
¿Hasta qué punto constituye esta novela la verdadera historia de Álvar Núñez Cabeza de Vaca? ¿Hasta qué punto es más fidedigno el novelista Posse que el cronista-protagonista de Naufragios? ¿Qué opina el mismo Posse? Yo diría que esta novela, como varias de las Nuevas Novelas Históricas, es dialógica. Por una parte, las memorias de Cabeza de Vaca escritas en la novela parecen más completas y más verosímiles que Naufragios con la explicación del miedo a la Inquisición y a los oficiales imperiales. Por otra parte, El largo atardecer del caminante es una novela. Todo lo que le sucede a Cabeza de Vaca en Sevilla durante el último año de su vida no proviene de ninguna crónica, de ninguna autobiografía, ni de ningún texto histórico: es invención del novelista. De ahí la importancia de la trama amorosa entre el protagonista y la joven Lucinda. El suspenso de la novela se deriva del amor que siente el protagonista, de sus celos al enterarse de que Lucinda tiene un novio medio moro, y de su plan de asesinar a éste. El desenlace inesperado es que el novio resulta ser un judaizante y que los dos van a escaparse pronto de España. La importancia del novelista entrenado en la fabulación se simboliza con la presencia del Marqués de Bradomín, fabulador por antonomasia. ¿Cuál es mi propia conclusión? Igual que Hayden White, creo que hay que desconfiar de los historiadores. Al mismo tiempo, concuerdo con Posse en que la esencia del novelista es su talento para fabular, es decir, inventar o mentir. Por lo tanto, como crítico literario, me toca elogiar la última novela de Posse como obra de arte pero para averiguar la verdad, toda la verdad y nada más que la verdad, confio más en los futuros historiadores.

BibLIOGRAFIA

Abel Posse, El largo atardecer del caminante. Buenos Aires: Emecé, 1992. 